\title{
Anticestodal efficacy of Psidium guajava against experimental Hymenolepis diminuta infection in rats
}

\author{
Temgenmogla V. Tangpu, Arun K. Yadav
}

\author{
Department of Zoology, \\ North-Eastern Hill University, \\ Shillong 793022, India. \\ Received: 3.5.2005 \\ Revised: 7.7.2005 \\ Accepted: 4.10.2005 \\ Correspondence to: \\ Arun K. Yadav \\ E-mail: akynehu@hotmail.com
}

\begin{abstract}
Objective: To investigate the anticestodal efficacy of Psidium guajava L. leaf extract. Materials and Methods: Anticestodal efficacy was evaluated using experimental Hymenolepis diminuta infection in rats. The leaf extract was administered orally to different groups of experimentally infected $H$. diminuta infections in rats. The efficacy was adjudged in terms of parasite eggs/g (EPG) of faeces count before and after treatment, direct count of surviving worms remaining in small intestines after completion of treatment and by host clearance of parasite. In all the experiments, the effect of leaf extract was compared with a standard anticestodal drug, praziquantel (PZQ).

Results: The leaf extract showed reduction in parasite EPG of faeces count in a dosedependent manner. It further showed comparatively low recovery of worms including scolices in the small intestine and host clearance of parasite in a dose dependent manner. In all the experimental models the anticestodal efficacy of leaf extract was significantly comparable with that of PZQ.

Conclusion: The leaf extract of $P$. guajava possesses anticestodal efficacy. Study supports its folk medicinal use in the treatment of intestinal-worm infections in northeastern part of India.
\end{abstract}

KEY WORDS: EPG count, praziquantel, scolex.

\section{Introduction}

Psidium guajava L., belonging to the family Myrtaceae, is a widely distributed plant which has several medicinal uses: antifilarial, ${ }^{[1]}$ antidiarrheal, ${ }^{[2]}$ CNS depressant, ${ }^{[3]}$ anticough, ${ }^{[4]}$ antiamebic, antispasmodic, ${ }^{[5,6]}$ and antimicrobial activity. ${ }^{[7]}$ Its previously isolated constituents include ascorbic acid, ${ }^{[8]}$ fatty acids, ${ }^{|9|}$ tannins, phenols, triterpenes, essential oils, saponins, ${ }^{[10]}$ carotenoids, ${ }^{[11]}$ lectins, ${ }^{[12]}$ and flavonoids. ${ }^{[5]}$ In the northeastern part of India, various Naga tribes use fresh leaves water decoction of $P$. guajava (locally known as "motiram") as a common remedy for intestinal-worm infections. To substantiate the claims made by local people herein we report the in vivo anticestodal efficacy of $P$. guajava using experimental Hymenolepis diminuta infection in albino rats.

\section{Materials and Methods}

\section{Plant material and extraction}

P. guajava L. (Myrtaceae) fresh tender leaves were collected from the Mokokchung District of Nagaland (India) during October 2002 in the supervision of Dr. Jamir, Department of Botany, Nagaland University, Nagaland. A voucher specimen (AKY/001) has been deposited in the Department of Zoology, North-Eastern Hill University, Shillong. The plant material was dried in shade at $15-26^{\circ} \mathrm{C}$ and finely grounded into powdered form with the help of an electric grinder. The powdered material was hot-extracted in methanol at $40^{\circ} \mathrm{C}$ for approximately $48 \mathrm{~h}$. The solvent was removed by distillation under reduced pressure using rotatory vacuum evaporator; the residue was dried over anhydrous calcium chloride inside a desiccator and stored at $-20^{\circ} \mathrm{C}$ until further use. The yield of prepared extract was $23.68 \%$.

Animals

Albino rats of either sex were originally purchased from M/s Fanindra Nath Chakravorty, Kolkata, and the stock was inbred in the animal house for several years. Animals (100$120 \mathrm{~g}$ ) of either sex were used in the study. They were kept under the standard environmental conditions with food and water ad libitum. All the animal experiments were performed following the approval of study protocols by the Institutional Animal Ethics Committee.

Acute toxicity study

Eighteen rats were divided into three groups (six rats per group). Groups I and II were treated with the leaf extract at 3200 and $6400 \mathrm{mg} / \mathrm{kg}$ body weight dissolved in water. Group III served as the control group, which received water (the vehicle for the extract). The animals were kept under observation for $72 \mathrm{~h}$ period for mortality; they were further 
observed for any changes in their body weight, body temperature, and food and water uptake over a period of 2 weeks.

\section{Experimental design}

Anticestodal efficacy was adjudged on the basis of parasite eggs/g (EPG) of faeces count before and after treatment, ${ }^{[13]}$ direct count of surviving worms including scolices (\% worm recovery) remaining in small intestines after completion of treatment, ${ }^{[14]}$ and by host clearance of parasite. These were calculated in percentage as follows:

Percentage difference in EPG count $=($ mean EPG at pretreatment - mean EPG at post-treatment) X 100/(mean EPG at pretreatment)

Percentage worm recovery rate $=$ number of worms recovered at necropsy X 100/number of cysticercoids given

Percentage host clearance $=$ number of hosts found devoid of worms X 100/number of hosts infected with worms

The infection of $H$. diminuta was maintained in rats by alternating the hosts using wheat flour beetles, Tribolium confusum (Tenebrionidae), as the intermediate host. ${ }^{[15]}$ Beetles were starved for 3 days and later allowed to feed for $72 \mathrm{~h}$ on the sieved flour powder mixed with the faecal matter containing $H$. diminuta eggs obtained from the gravid segments of parasites, which were maintained in rats in our laboratory. Beetles were later maintained at room temperature with free access to flour until dissected. After 12 days of feeding gravid segments, the cysticercoids (larval stage) were obtained by dissecting the infected beetles in phosphatebuffered saline ( $\mathrm{pH}$ 7.3). Each rat was inoculated with four cysticercoids suspended in $1 \mathrm{ml}$ of saline using a feeding tube and later maintained in separate cages as described by Dixon and Arai. ${ }^{[15]}$ For each experiment rats were divided into six groups, comprising six animals in each group. Group I rats served as infected, untreated controls. Groups II-V were treated with $1600,800,400$, and $200 \mathrm{mg} / \mathrm{kg}$ dose of leaf extract. Group VI was given $5 \mathrm{mg} / \mathrm{kg}$ of praziquantel (PZQ) as a standard anticestodal drug. Different doses of leaf extract and PZQ were calculated out as per the body weight of animals that were dissolved in $1 \mathrm{ml}$ of water and later administered to each animal with the help of a feeding tube. Administration of leaf extracts and PZQ to the infected rats was done consecutively from day 26 to 28 and day 36 to 38 .

On the 18th-day postinoculation, faecal examination revealed that all the rats were infected; their EPG of faeces was monitored using the modified Mc Master method. ${ }^{[13]}$ EPG count was done for 3-day pretreatment (day 18-20), 3-day post-treatment (day 26-28) and a follow-up examination of the EPG count was done again for another 3 days (day 3638), i. e., after 1 week of the previous EPG count.

Statistical analysis

Statistical analysis was performed using two-way and oneway ANOVA followed by Dunnett's test. The significance of difference was accepted at $\mathrm{P}<0.01$.

\section{Results}

The results are presented in Tables 1-3. The mean EPG count did not vary much in the control group throughout the experimental period (Table 1). Lower doses of leaf extract had fewer effects on mean EPG counts; whereas $800 \mathrm{mg} / \mathrm{kg}$ dose reduced the EPG count by $55.73 \%$ and $85.37 \%$ at days 26-28 and 36-38, respectively. A dose of $1600 \mathrm{mg} / \mathrm{kg}$ body weight of leaf extract showed maximum reduction in the EPG count, $71.23 \%$ and $92.17 \%$ at days $26-28$ and $36-38$, respectively. The standard anticestodal drug PZQ decreased the mean EPG counts by $82.37 \%$ and $96.39 \%$ during the similar days' regime. Treatment with 800 and $1600 \mathrm{mg} / \mathrm{kg}$ dose of leaf extracts resulted into comparatively low worm recovery rates (25\% and $16.75 \%$, respectively); PZQ reduced the worm recovery rate by $12.5 \%$. Further, the 800 and 1600 $\mathrm{mg} / \mathrm{kg}$ of dose showed a $16.66 \%$ and $33.33 \%$ host clearance as compared with PZQ, in which it was observed to be $66.66 \%$. The results thus indicate that leaf extract of $P$. guajava is quite effective against $H$. diminuta parasite.

In the acute toxicity study, 3200 and $6400 \mathrm{mg} / \mathrm{kg}$ body weight dose of leaf extract administered to two groups of rats did not show any mortality during the $72 \mathrm{~h}$ period of observation. The control and plant-extract-treated groups showed normal increases in body weight $(6.29 \%, 3.4 \%$, and

\section{Table 1}

Efficacy of $P$. guajava leaf extract on EPG of faeces count of $\boldsymbol{H}$. diminuta infection in rats

\begin{tabular}{|c|c|c|c|c|c|c|c|}
\hline \multirow[t]{2}{*}{ Group } & \multicolumn{3}{|c|}{ EPG counta } & \multicolumn{2}{|c|}{ Difference in EPG count } & \multicolumn{2}{|c|}{ \% Reduction in EPGa } \\
\hline & $\begin{array}{l}\text { Pretreatment }(Z) \\
\quad(\text { Days 18-20) }\end{array}$ & $\begin{array}{l}\text { Post-treatment (A) } \\
\text { (Days 26-28) }\end{array}$ & $\begin{array}{c}\text { Post-treatment (B) } \\
(\text { Days 36-38) }\end{array}$ & $Z$ and $A$ & $Z$ and $B$ & $Z$ and $A$ & $Z$ and $B$ \\
\hline Control & $16866.68 \pm 269.44$ & $16822.22 \pm 283.72$ & $16822.22 \pm 422.22$ & $44.46 \pm 16.66$ & $44.46 \pm 15.36$ & $0.26 \pm 0.10$ & $0.26 \pm 0.09$ \\
\hline \multicolumn{8}{|c|}{ Extract $(\mathrm{mg} / \mathrm{kg})$} \\
\hline 1600 & $17044.44 \pm 270.34$ & $4911.12 \pm 160.24$ & $1000.00 \pm 115.48$ & $12133.34 \pm 148.00$ & $16044.44 \pm 226.23$ & $71.23 \pm 0.51$ & $92.17 \pm 0.52$ \\
\hline 800 & $17133.34 \pm 901.84$ & $7600.00 \pm 443.90$ & $2533.34 \pm 501.84$ & $9533.34 \pm 151.56$ & $14600.00 \pm 241.27$ & $55.73 \pm 1.42$ & $85.37 \pm 2.40$ \\
\hline 400 & $17133.34 \pm 133.34$ & $11222.22 \pm 1371.98$ & $34200.00 \pm 203.66$ & $5911.12 \pm 493.24$ & $12933.34 \pm 746.57$ & $35.28 \pm 3.94$ & $75.42 \pm 0.31$ \\
\hline 200 & $17200.00 \pm 1488.84$ & $12355.56 \pm 978.54$ & $5000.00 \pm 983.32$ & $4844.44 \pm 544.24$ & $12200.00 \pm 946.06$ & $28.12 \pm 2.06$ & $70.46 \pm 4.07$ \\
\hline \multicolumn{8}{|c|}{ Praziquantel } \\
\hline $5 \mathrm{mg} / \mathrm{kg}$ & $17022.24 \pm 699.56$ & $3000.00 \pm 66.68$ & $600.00 \pm 155.46$ & $14022.23 \pm 343.89$ & $16422.23 \pm 306.76$ & $82.37 \pm 0.17$ & $96.39 \pm 0.58$ \\
\hline
\end{tabular}

aValues are mean \pm SEM. $\mathrm{n}=6$ animals in each group. $\mathrm{P}<0.01$ (two-way ANOVA). 
Table 2

Efficacy of $\boldsymbol{P}$. guajava leaf extract on worm recovery rate of $H$. diminuta infections in rats

\begin{tabular}{|c|c|c|c|c|}
\hline Group $\begin{array}{r}N \\
\text { Cys }\end{array}$ & $\begin{array}{l}\text { Number of } \\
\text { Cysticercoids / } \\
\text { rat }\end{array}$ & $\begin{array}{c}\text { Mean } \pm S E M \\
\text { of recovered } \\
\text { worms / rat } \\
(\text { range) }\end{array}$ & $\begin{array}{l}\text { Worm } \\
\text { recovery } \\
\text { (\%) }\end{array}$ & $\begin{array}{c}\text { Host } \\
\text { clearance } \\
\text { (\%) }\end{array}$ \\
\hline Control & 4 & $4.00 \pm 0.00(0)$ & 100.00 & 0.00 \\
\hline \multicolumn{5}{|l|}{ Extract } \\
\hline $1600 \mathrm{mg} / \mathrm{kg}$ & $\mathrm{kg}$ & $0.67 \pm 0.21(0-1)$ & 16.75 & 33.33 \\
\hline $800 \mathrm{mg} / \mathrm{kg}$ & 4 & $1.00 \pm 0.26 \quad(0-2)$ & 25 & 16.66 \\
\hline $400 \mathrm{mg} / \mathrm{kg}$ & 4 & $1.34 \pm 0.21(1-2)$ & 33.5 & 0 \\
\hline $200 \mathrm{mg} / \mathrm{kg}$ & 4 & $2.34 \pm 1.00(2-3)$ & 58.5 & 0 \\
\hline \multicolumn{5}{|l|}{ Praziquantel } \\
\hline $5 \mathrm{mg} / \mathrm{kg}$ & 4 & $0.50 \pm 0.34(0-2)$ & 12.5 & 66.66 \\
\hline One-way & $\mathrm{F}$ & 0.2843 & & \\
\hline \multirow[t]{2}{*}{ ANOVA } & $\mathrm{P}$ & $>0.01$ & & \\
\hline & $d f$ & 5,30 & & \\
\hline
\end{tabular}

$\mathrm{n}=6$ animals in each group.

\section{Table 3}

Changes in body weight in rats after treatment with $P$. guajava leaf extract

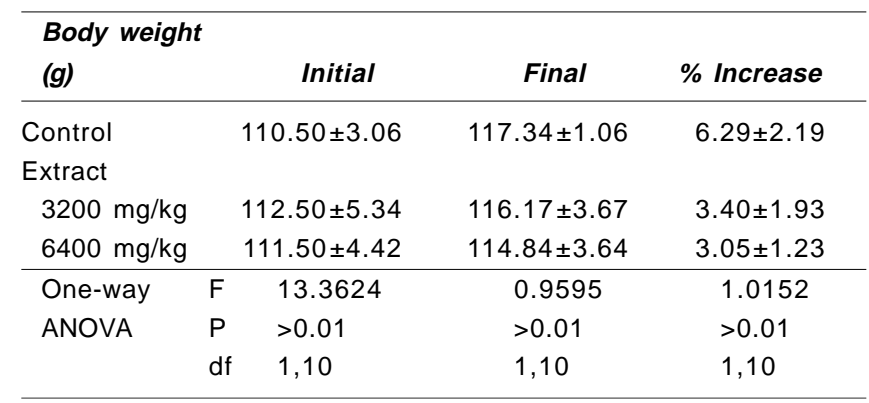

$\mathrm{n}=6$ animals in each group; values are mean \pm SEM.

$3.05 \%$, respectively, which were not significantly different from each other) (Table 3). No significant differences in body temperature, food, and water intake from the controls were found in the animals.

\section{Discussion}

The northeast part of India, which is inhabited by various tribes, has unique tradition of using plant materials or plantbased preparations for various remedies. $P$. guajava is among one such commonly used plants whose young, tender leaves have a reputation of being efficacious against intestinal-worm infections in the Naga tribes of Northeast India. The current study was therefore carried out to assess its acclaimed efficacy, employing the $H$. diminuta-albino rat experimental model.
The counting of EPG, recovery of worms, and percentage of host clearance at necropsy after the treatment are conventional methods to establish the anticestodal efficacy of an agent ${ }^{[14,15]}$.

In the present study, methanol extract of the leaves of $P$. guajava revealed a significant level of anticestodal activity against experimentally induced $H$. diminuta infections. The results indicate that the efficacy of leaf extract is dosedependent. Lower worm counts after treatment periods as recorded in the study may be owing to loss of worm and/or process of destrobilation. Dixon and Arai, ${ }^{\mid 15]}$ in their study on effect of anthelmintic on $H$. diminuta, reported that this may be owing to either expulsion of adult worms or destrobilation by leaf extract. It is known that the cestodes usually undergo the process of destrobilation if exposed to any anthelmintic drug or if owing to any physiological stress in the intestine. ${ }^{15]}$ The recovery of low number of worms on necropsy after treatment and reduction in EPG count further substantiates the claim regarding the anticestodal efficacy of leaf extract. The worm recovery rate decreased subsequently on increasing the dose of leaf extract. Similar trends were observed with regard to percentage host clearance, which increased with an increase in the dose of leaf extract

In the acute toxicity study, a dose of $6400 \mathrm{mg} / \mathrm{kg}$ given singly as well as twice orally did not cause any mortality or any changes in body temperature, body weight, and food and water intake. This dose is four times that of the highest dose of the extract $(1600 \mathrm{mg} / \mathrm{kg})$ administered to the rats. The control and plant-extract-treated groups showed normal increases in body weight, which were not significantly different from each other. The preliminary observations indicate that the leaf extract is nontoxic in nature. However, the toxicity of extract needs to be further investigated with regard to other parameters.

In conclusion, the results of the present study indicate that leaf extract of $P$. guajava possesses significant level of anticestodal efficacy, which validates its use in folk medicine. This plant has a potential for exploring its activity profile against other helminth parasites too.

\section{Acknowledgments}

Financial grants from UGC-DRS III and laboratory facilities by the institution to carry out this work are gratefully acknowledged.

\section{References}

1. Temjenmongla, Yadav AK. Filaricidal efficacy of some folklore medicinal plants against Setaria cervi (Nematoda: Filarioida). Proc Zool Soc 2003;56:57-61.

2. Lutterodt GD. Inhibition of gastrointestinal release of acetylcholine by quercetin as a possible mode of action of Psidium guajava leaf extracts in the treatment of acute diarrhoeal disease. J Ethnopharmacol 1989;25:235-47.

3. Meckes M, Calzada F, Tortoriello, Gonzalez JL, Martinez M. Terpenoids isolated from Psidium guajava hexane extract with depressant activity on central nervous system. Phytotherapy Res 1996;10:600-3.

4. Jairaj $P$, Khoohaswan $P$, Wongkrajang $Y$, Peungvicha $P$, Suriyawong $P$, Saraya, ML, et al. Anticough and antimicrobial activities of Psidium guajava Linn. leaf extract. J Ethnopharmacol 1999;67:203-12.

5. Lozoya, X, Reyes-Morales H, Chavez-Soto MA, Martinez-Garcia Mdel C, Soto-Gonzalez Y, Doubova SV. Intestinal anti-spasmodic effect of a phytodrug of Psidium guajava folia in the treatment of acute diarrheic disease. $\mathrm{J}$ Ethnopharmacol 2002;83:19-24.

6. Tona L, Kambu K, Ngimb N. Antiamoebic and spasmolytic activities of 
extracts from some antidiarrhoeal traditional preparations used in Kinshasa, Congo. Phytomed 2000;7:31-8.

7. Qadan F, Thewaini AJ, Ali DA, Afifi R, Elkhawad A, Matalka KZ. The antimicrobial activities of Psidium juajava and Juglans regia leaf extracts to acne-developing organisms. Am J Chin Med 2005;33:197-204.

8. Nogueira JN, Soybihe Sobrinho J, Vencosvsky R, Fonseca H. Effect of storage on the levels of ascorbic acid and beta-carotene in freeze-dried red guava (Psidium guajava L). Arch Latinoam Nutr 1978;28:363-377.

9. Opute FI. The component fatty acids of Psidium guajava seed fats. J Sci Food Agricul 1978;29:737-8.

10. Cuellar AC, Lara RA, Zayas JP. Psidium guajava L. tamizaje fitoquimico y estudio del aceite esencial. Rev Cubana Farmacia 1984;18:92-9.

11. Mercadante AZ, Steck A, Pfande, H. Carotenoids from guava (Psidium guajava L.): Isolation and structure elucidation. J Agric Food Chem 1999;47:145-51.

12. Coutino-Rodriguez R, Hernandez-Cruz P, Giles-Rios H. Lectins in fruits having gastrointestinal activity: their participation in the hemagglutinating property of Escherichia coli 0157: H 7. Arch Med Res 2001;32:251-7.

13. Anonymous. Manual of Veterinary Parasitological Techniques. Technical Bulletin No. 18. London: H.M.S.O.; 1977.

14. Rim HJ, Ha JH, Kim SJ. Experimental study on the therapeutic effect of Praziquantel (Embay 8440) in rats experimentally infected with Clonorchis sinensis. Kisaengchunghak Chapchi 1980;18:65-80.

15. Dixon BR, Arai, HP. Anthelmintic-induced destrobilation and its influence on calculated drug efficacy in Hymenolepis diminuta infections in rats. $\mathrm{J}$ Parasitol 1991;77:769-74.

\section{Pharmpedia.com: The Free Online Pharmaceutical Encyclopedia, a one stop resource for pharmaceutical information}

Pharmpedia.com is the free content open source online pharmaceutical encyclopedia that is written collaboratively by people from all around the world.

Pharmpedia.com is ventured by a group of pharmaceutical professionals who are associated with Academia, Industry, Research and Regulatory fields in North America and India. The objective of launching this online website is to bring the entire pharmaceutical information under one umbrella including online text books (Pharmpedia text books) and Course materials (Pharmpediaversity). This pharmaceutical encyclopedia information can be used freely. Currently authors from around world are working on more than 700 articles, text books and course materials.

This project is an open platform for enthusiastic pharmaceutical professionals to actively participate and contribute directly online on website to enrich this encyclopedia and attach their authorship to the articles they publish, which can also be updated by other authors on a continuous basis until a perfection of the content is achieved.

Enthusiastic contributors are encouraged to contact us for further information at: pharmpedia@gmail.com

\section{Call for Indian Pharmacologists:}

Pharmpedia.com - The Free Online Pharmaceutical Encyclopedia is currently looking for active contributors in the field of Pharmacology. Pharmpedia.com has strong belief in the expertise and knowledge of Indian pharmacologists. Pharmpedia.com solicits the support of Indian Pharmacologists in building up the basic content of pharmacology for its encyclopedia. Interested pharmacologists are requested to contact us at pharmpedia@gmail.com. 